Journal of Social Sciences 8 (2): 252-257, 2012

ISSN 1549-3652

(C) 2012 Science Publications

\title{
Access to Higher Education among High School Students: Challenges and Solutions
}

\author{
${ }^{1}$ Carol M. Trivette, ${ }^{2}$ Jennifer Wilson-Kearse, \\ ${ }^{3}$ Carl J. Dunst and ${ }^{1}$ Deborah W. Hamby \\ ${ }^{1}$ Orelena Hawks Puckett Institute 128 S. Sterling St., Morganton, NC 28655 \\ ${ }^{2}$ GEAR UP, Appalachian State University, DD Dougherty Hall, NC 28608, Boone \\ ${ }^{3}$ Orelena Hawks Puckett Institute, 8 Elk Mountain Rd. NC 28804, Asheville
}

\begin{abstract}
Problem statement: Although there have been increases in student enrollment in tertiary (university) educational settings in many countries, there continues to be students who experience challenges bridging secondary (high school) and university education. Approach: This study includes a description of strategies used in a Gaining Early Awareness and Readiness for Undergraduates Program (GEAR UP) that assisted students whose parents did not continue education beyond high school to pursue a college or university education. Results: The relationship between both student academic support and parent support of students attending college and students' participation in the college preparation activities (termed university preparedness) in 10 and 11th grades were examined. Conclusion: The analyses showed that higher levels of both types of supports are associating with higher student university preparedness scores and that parent-related supports proved especially important as a determinant of pursuing a tertiary degree.
\end{abstract}

Key words: Gaining Early Awareness and Readiness for Undergraduates Program (GEAR UP), Appalachian State University (ASU), tertiary degree, experience challenges

\section{INTRODUCTION}

Creating and expanding educational opportunities for children throughout the world has been a focus of international interest for years. According to the United Nations, the number of children completing primary school in nearly all countries worldwide has continued to increase for nearly two decades (ISMUN, 1964). Secondary school enrollment across the globe increased from 56-78\% in the last decade (Luisoni et al., 2005) and the number of students entering tertiary (university) educational institutions after completing a secondary education rose by 20 million people between 1990 and 1997 (UNESCO, 2003).

There are, however, still many challenges in creating educational opportunities for all students. For example, although the enrollment rate at tertiary schools is about $45 \%$ in most developed countries, the enrollment rate in developing countries is only 30\% (UNESCO, 2003). There also continues to be disparities in enrollment rates at the tertiary level based on gender (UNESCO, 2003) and socio-economic factors (Luisoni et al., 2005) which, among other factors, serve as deterrents to pursuing a university education (Cabrera and Nasa, 2001; Phinney et al., 2006; Walpole, 2003).

Early awareness and readiness for postsecondary education: In the United States, youth from families whose parents have not pursued formal education beyond high school and who at the same time are economically disadvantaged, face many barriers and challenges to pursuing a tertiary (university) education (Choy, 2001; Deil-Amen et al., 2005; Tym et al., 2004). In response to these barriers and challenges, the United States federal government authorized funding for the Gaining Early Awareness and Readiness for Undergraduates Programs (GEAR UP) to provide students, teachers and schools the resources to encourage college or university enrollment among all students (AISD, 2007; Muraskin, 2003; Standing et al., 2008). The primary goal of GEAR UP is to increase the number of low-income students who are prepared to enroll and succeed in their postsecondary education (Deil-Amen et al., 2005).

This study includes findings from data collected in one school district in western North Carolina in the USA that is currently participating in the Appalachian 


\section{J. Social Sci., 8 (2): 252-257, 2012}

State University (ASU) GEAR UP project (WilsonKearse, 2010). ASU GEAR UP works with middle schools and high schools in four school districts located in high poverty areas where more than 50\% of the students are eligible for free or reduced price lunches (a proxy measure for low socio-economic status). Data collected in the 10th grade in this school district showed that $60 \%$ of the students and $66 \%$ of their parents indicated that the youth would attend and receive a four year college degree after graduation from high school (ERIC, 2007; Trivette, 2010). Yet, the most recent data for these students show that only $41 \%$ of 12 th grade students in this school district have taken the college or university entry tests (SATs or ACTs) needed to apply to most four year colleges or universities in the United States (ERIC, 2007; Trivette, 2010). It is worth noting that only $13 \%$ of the adults in the county where the school district is located and where the students reside have at least a four year college or university degree (NCDC, 2011).

GEAR UP activities and supports: The disconnect between what students and parents desire as educational outcomes and the reality of reaching those outcomes, is what GEAR UP attempts to reconcile (Roderick et al., 2008). The program bridges the disconnect through increased knowledge, expectations and preparation for post-secondary education by providing different kinds of supports to students and their parents. Students voluntarily participate in GEAR UP activities which include: After school tutoring, one-on-one or group mentoring, homework assistance and academic enrichment activities (Conley, 2009). GEAR UP offers parents opportunities to participate in group or individual counseling sessions and advising that focus on awareness of post-secondary educational opportunities, workshops on financial aid, information about the necessary high school requirements for postsecondary education and presentations on university admissions requirements (Gibson and Jefferson, 2006). GEAR UP begins working with students in the 6th or 7th grades and continues providing supports to the students throughout high school (Muraskin, 2003).

There are certain attainments that need to be achieved as early as 6 and 7 th grades and which reach a critical point during high school. In order for students to attend college or a university, students must first be able to perform at an appropriate academic level to qualify for advanced high school classes and pass exams needed to apply to postsecondary education settings (Conley, 2007; Roderick et al., 2008). As a result, academic tutoring and mentoring are extremely important GEAR UP supports that students can use to improve their academic standing (Muraskin, 2003).
In order to help parents be better able to support their high school students as part of their children applying to college, GEAR UP provides supports that focus on enhancing parent knowledge of postsecondary schools options, procedures for obtaining college financial aid and the information required for the role parents play in assisting their children in the college application process (Choy, 2001; Deil-Amen et al., 2005; Gibson and Jefferson, 2006). There are also college and university-related activities that help high school students be prepared to apply for enrollment and succeed in college (Conley, 2007; 2009). These GEAR UP activities include student visits to colleges or universities, information about the application process, university academic planning and discussions about possible career options (Muraskin, 2003). These can be important experiences for students who have never visited a college campus or had a family member complete a college or university degree.

The analysis reported in this study examined the relationship between both students' engagement in activities that support academic achievement, parent support for students attending college and students' participation in college preparedness activities that lead to applying for and enrolling in a college or university. The focus of analysis was the empirical relationship between both school-related students' academic and parent supports and students' participation in college preparation activities (termed university preparedness).

Participants: The participants were 267 students who attended high school in one school district in western North Carolina, USA. Participants were part of a cohort of students enrolled in GEAR UP beginning in the 6th or 7th grades, where data were collected on the students in the 10 and 11th grades. Eighty percent of the students were Caucasian and $10 \%$ were either African American or Asian American.

Measures: The data used for analysis in this study came from records maintained on individual students and their parents by GEAR UP counselors who recorded which of 15 activities students and parents attended on a monthly basis. The two independent variables were: (a) the academic supports provided by GEAR UP counselors, teachers and other school personnel to the students and (b) the GEAR UP and school-related supports provided to the students' parents. Student academic support included the amount of time students received academic tutoring, homework assistance, academic enrichment activities and student mentoring by teachers or GEAR UP staff. Parent university-related support included the amount of time parents participated in activities with GEAR UP staff and included counseling about personal or family concerns, advising parents on post 


\section{J. Social Sci., 8 (2): 252-257, 2012}

high school educational opportunities and procedures for obtaining financial resources.

The dependent measure was the hours of student engagement in different types of university-related preparedness activities during a school year. Student university preparedness included personal collegerelated counseling, postsecondary academic planning and advising, career counseling, university visits and university student shadowing. The dependent measure was the total number of hours of student engagement in the activities during the 10th and 11 th grades respectively.

\section{MATERIALS AND METHODS}

A 2 Between Grade (10th vs. 11th) X 2 Levels of Student Academic Support (Low vs. High) ANOVA and a 2 Between Grade (10th vs. 11th) X 2 Levels of Parent Support (Low vs. High) ANOVA were used to evaluate the separate effects of both types of support on student university preparedness. A 2 Between Level of Student Academic Support (Low vs. High) X 2 Between Level of Parent Support (Low vs. High) ANOVA with student university preparedness as the dependent measure was used to evaluate the combined effects of both student and parent support on the dependent measure in both the 10 and 11th grades.

Low or high support (either student academic or parent related) was determined by constituting groups of students who themselves or their parents received little or no support (low) or received some or considerable amounts of support (high). Table 1 shows the hours of both types of support procured in the 11th and 12th grades. Comparisons of the hours of supports for the low Vs high support groups showed statistically significant differences and between group Cohen's d effect sizes all exceeding 2.00. The fact that there were so many more hours of student academic support compared to parent related supports was not unexpected given the fact that GEAR UP offered more activities to students then to their parents.

The main focus of analysis was the (a) between condition comparisons and contrasts and (b) the interactions between the different research factors. Cohen's d effect sizes for the mean differences between comparative or contrasting conditions were used for substantive interpretation of the results. The use of effect sizes rather than statistical significance is the recommended metric for interpreting both the magnitude of the differences between groups and for interpreting the nature of interaction effects (Hill et al., 2008; Vacha-Haase and Thompson, 2004; Valentine and Cooper, 2003). Cohen's d was computed as the difference between the means for two groups divided by the pooled standard deviation for the two means (Cooper and Hedges, 1994).
Table 1: Mean number of hours of student academic supports and parent university-related supports provided to the study participants

\begin{tabular}{lrrrrrr}
\hline & Low support & \multicolumn{2}{l}{ High support } & & \\
& ----------- & ---------- & \\
Type of support & Mean & SD & Mean & SD & t-test & Cohen's d \\
\hline Tenth grade & & & & & & \\
Student academic support & 17.03 & 25.14 & 137.83 & 61.50 & $21.26^{*}$ & 2.57 \\
Parent university support & 0.86 & 0.74 & 3.02 & 0.57 & $20.47^{*}$ & 3.26 \\
Eleventh grade & & & & & & \\
Student academic su pport & 16.10 & 18.33 & 155.93 & 79.86 & $15.14^{*}$ & 2.43 \\
Parent university support & 1.25 & 0.56 & 3.21 & 0.54 & $15.00^{*}$ & 3.58 \\
\hline$* ; p<0.0001$ & & & & & &
\end{tabular}

\section{RESULTS}

Student academic support findings: Figure 1 shows the results for the relationship between low and high levels of student-related academic support and student university preparedness in both the 10th and 11th grades. The results showed that there were increases in student university preparedness between the 10th and 11 th grades for students receiving either low $(d=0.32)$ or high $(\mathrm{d}=0.62)$ levels of academic support, where the increases were more pronounced among the students receiving higher levels of academic support. This is discerned from the difference in the effect sizes between the 10 th and 11 th grades $(d=0.62-0.32=0.30)$. As can be seen from inspection of the findings shown in Fig. 1, there was a between grade $\mathrm{x}$ between level of student support interaction. This is evidenced by the size of effects for the differences between the high vs. low student support preparedness scores in the 11 th grade $(\mathrm{d}$ $=0.41$ ) and the larger difference in the university preparedness scores for the high Vs low student support groups in the 11th grade $(\mathrm{d}=0.56)$. The findings showed that the influences of student academic support on university preparedness scores were greater in the 11 th compared to the 10 th grade.

Parent-related support findings: The relationship between differences in the supports provided to the students' parents and the students' university preparedness scores in grades 11 and 12 is shown in Fig. 2. There were increases in student preparedness scores between the 10th and 11th grades for both the low $(\mathrm{d}=0.48)$ and high $(\mathrm{d}=0.57)$ parent support groups. In both grades, however, student university preparedness scores were higher among students whose parents received more university-related supports from GEAR UP in both the 10th $(\mathrm{d}=0.51)$ and 11 th $(\mathrm{d}=$ 0.41) grades. As was found in the analyses of the student academic support data, the influences of parent support on student university preparedness was more pronounced in the 11th compared to the 10th grades. In the absence of parent university-related supports, higher levels of student academic support positively affected student university preparedness in both grades. 


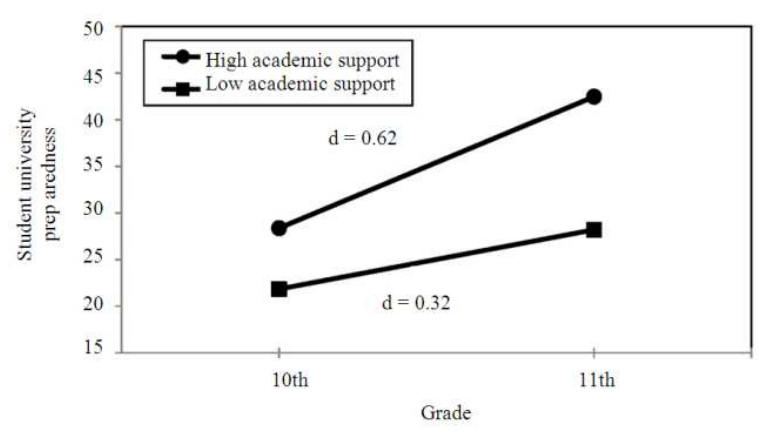

Fig. 1: Relationship between student academic support and student university preparedness

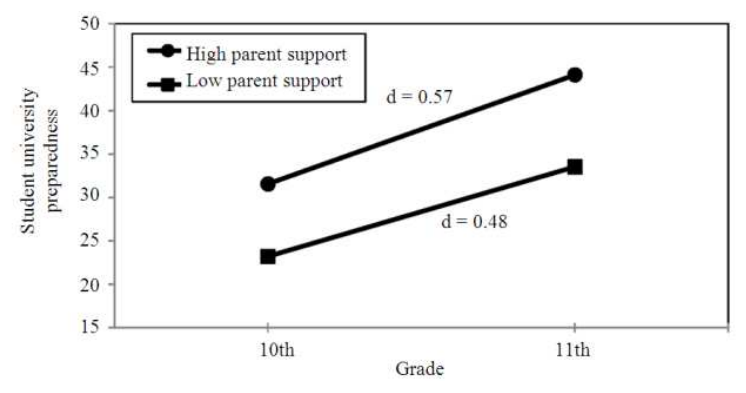

Fig. 2: Relationship between parent support and student university preparedness

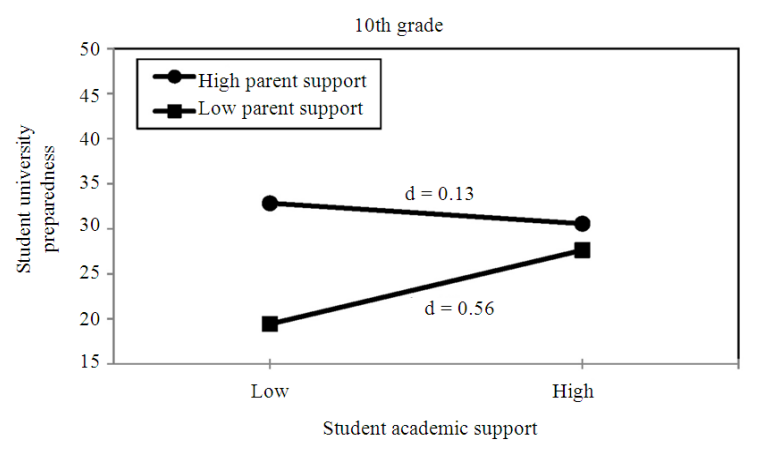

Fig. 3: Relationship between parent and student academic support on 10th grade student university preparedness

Student and parent support findings: Figure 3, 4 shows, respectively, the relationships between both student academic support and parent university-related support and student university preparedness in the 10th and 11th grades. In both analyses, higher levels of parent supports were associated with higher student university preparedness scores regardless of the level of student academic support. In contrast, high levels of student academic support moderated the relationship between parent support and student university preparedness as evidenced by the student $\mathrm{x}$ parent support interactions in both the 11 and 12 th grades.

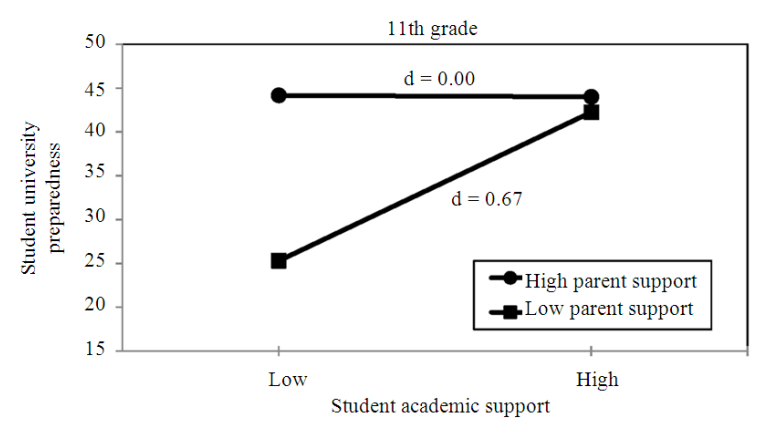

Fig. 4: Relationship between parent and student academic support on 11th grade student university preparedness

\section{DISCUSSION}

The university preparatory program described in this study is intended to provide all students, but especially students from families with socio-economic backgrounds which have traditionally been a barrier to pursuing postsecondary education, supports that encourage high school students to engage in activities that prepare them to enroll in a college or university. The analyses of the relationship between student academic supports, parent university-related supports and student engagement in activities that were indicators of pursuing secondary education showed that student academic and parent-related supports both individually and in combination were related to the number of hours students pursued increased knowledge of university-related requirements and activities related to university preparedness. Of particular note is the fact that the supports provided by the GEAR UP staff to the parents, although quit limited, nonetheless were related to student university preparedness both in the 10th and 11th grades in the absence of student academic supports. This finding highlights the importance of parents encouraging their children to pursue a university education (Dennis et al., 2005).

The fact that the hours students engaged in university preparedness activities was greater in the 11th grade compared to the 10th grade was not unexpected. At least in high schools in the USA, the 11th grade is an important transition point between considering the possibility of attending a university (10th grade) and completing the necessary steps to apply for postsecondary education (12th grade) (Conley, 2009). Most students who plan to pursue a university education engage in earnest in activities necessary to fulfill the goal of attending a university during the last few years of high school (Dennis et al., 2005). 
The results reported in this study showed that GEAR UP, at least as implemented in the school district constituting the focus of analysis, provided and offered the kinds of student and parent supports that provided high school students who otherwise might not consider postsecondary education a reasonable option, opportunities to engage in university preparedness activities. GEAR UP as implemented in this one school district was successful in terms of achieving part of its mission and goals. Data being collected on the students in the 12th grade will permit a better determination of how well GEAR UP influences student application and enrollment in a postsecondary educational institution.

Placed in the context of other GEAR UP initiatives (Muraskin, 2003; Standing et al., 2008) as well as other programs designed to encourage high school students to consider the value and benefits of a postsecondary education (Choy, 2001; Conley, 2009), the experiences and lessons learned from the initiative described in this highlights the importance of recognizing the fact that student decisions to pursue postsecondary education are influenced by both school- and family-related supports (Choy et al., 2000; Dennis et al., 2005; Mahoney et al., 2003; Phinney et al., 2006). An important next step in understanding which supports are most important is to unpack the activities that GEAR UP offers to isolate which activities under which conditions are associated with optimal student benefits.

\section{CONCLUSION}

The kinds of activities used by GEAR UP to encourage students to pursue postsecondary education were effective in engaging students in college and university-related preparedness activities. This included both student academic supports and parent supports needed to help their children achieve their postsecondary education aspirations. The findings highlighted the relative importance of supports to the students' parents (Dennis et al., 2005).

The preparation of this article was supported in part by the Gaining Early Awareness and Readiness for Undergraduate Programs (GEAR-UP) through Appalachian State University, Boone, NC, USA. The opinions expressed, however, are those of authors and are not endorsed by GEAR-UP at ASU.

\section{REFERENCES}

AISD, 2007. AUSTIN, Texas: GEAR UP austinimpacting lives project, 2005-2006. Austin Independent School District, AUSTIN, TX.
Cabrera, A.F. and S.M.L. Nasa, 2001. On the path to college: Three critical tasks facing America's disadvantaged. Res. Higher Educ., 42: 119-149.

Choy, S.P., 2001. Students whose parents did not go to college: Postsecondary access, persistence, and attainment. Findings from the condition of education, 2001. National Center for Education, Washington, DC.

Choy, S.P., L.J. Horn, A.M. Nunez and X. Chen, 2000. Transition to college: What helps at-risk students and students whose parents did not attend college. New Directions Ins. Res., 27: 45-63. DOI: 10.1002/ir.10704

Conley, D., 2009. Creating college readiness: profiles of 38 schools that know how. Educational Policy Improvement Center, Eugene, OR.

Conley, D.T., 2007. Redefining college readiness. Educational Policy Improvement Center, Eugene, OR.

Cooper, H. and L.V. Hedges, 1994. The Handbook of Research Synthesis. 1st Edn., Russell Sage Foundation, New York, ISBN-10: 0871542269, pp: 573.

Deil-Amen, R., R. Prabhu, P.T. Terenzini and A. Cabrera, 2005. Reawakening the dream deferred: Can comprehensive intervention programs increase college awareness among at-risk students? National Council for Community and Education Partnerships, Washington, DC.

Dennis, J.M., J.S. Phinney and L.I. Chuateco, 2005. The role of motivation, parental support, and peer support in the academic success of ethnic minority first-generation college students. J. College Student Dev., 46: 223-236.

ERIC, 2007. Using EXPLORE[R] and PLAN[R] data to evaluate GEAR UP programs. ACT, Inc. Iowa City, IA.

Gibson, D.M. and R.N. Jefferson, 2006. The effect of perceived parental involvement and the use of growth-fostering relationships on self-concept in adolescents participating in GEAR UP. Adolescence, 41: 111-125.

Hill, C.J., H.S. Bloom, A.R. Black and M.W. Lipsey, 2008. Empirical benchmarks for interpreting effect sizes in research. Child Dev. Perspectives, 2: 172177. DOI: 10.1111/j.1750-8606.2008.00061.x

ISMUN, 1964. Youth and the United Nations. International Student Movement for the United Nations, Geneve.

Luisoni, P., M. Zitterbart, M. Amadio and B. Deluermoz, 2005. Quality education for all young people: Reflections and contributions emerging. Proceedings of the 47th International Conference on Education of UNESCO, Sep. 8-11, UNESCO Geneva, Switzerland. 
Mahoney, J.L., B.D. Cairns and T.W. Farmer, 2003. Promoting interpersonal competence and educational success through extracurricular activity participation. J. Educ. Psychol., 95: 409-418. DOI: 10.1037/0022-0663.95.2.409

Muraskin, L., 2003. National evaluation of GEAR UP: A summary of the first two years (PPSS-Doc-200313). U.S. Department of Education, Washington, DC.

NCDC, 2011. Allegheny County (NC). North Carolina Department of Commerce, Raleigh, NC.

Phinney, J.S., J. Dennis and S. Osorio, 2006. Reasons to attend college among ethnically diverse college students. Cultural Diversity Ethnic Minority Psychol., 12: 347-366. PMID: 16719582

Roderick, M., J. Nagaoka, V. Coca, E. Moeller and K. Roddie et al., 2008. From high school to the future: Potholes on the road to college. Consortium on Chicago School Research, Chicago, IL.

Standing, K., D. Judkins, B. Keller, A. Shimshak and Westat, 2008. Early outcomes of the GEAR UP program: Final Report. U.S. Department of Education, Office of Planning, Evaluation and Policy Development, Washington, DC.

Trivette, C.M., 2010. GEAR-UP student and parent data: 2009-2010. Orelena Hawks Puckett Institute, Morganton, NC.
Tym, C., R. McMillion, S. Barone and J. Webster, 2004. First-generation college students: A literature review. Texas Guaranteed Student Loan Corporation, Round Rock, TX.

UNESCO, 2003. Gender and Education for All: The Leap to Equality. Summary Report. 1st Edn., Unesco, Paris, pp: 33.

Vacha-Haase, T and B. Thompson, 2004. How to estimate and interpret various effect sizes. J. Counsel. Psychol., 51: 473-481. DOI: 10.1037/0022-0167.51.4.473

Valentine, J.C. and H. Cooper, 2003. Effect size substantive interpretation guidelines: Issues in the interpretation of effect sizes. What Works Clearinghouse, Washington, DC.

Walpole, M., 2003. Socioeconomic status and college: How SES affects college experiences and outcomes. Rev. Higher Educ., 27: 45-73. DOI: 10.1353/rhe.2003.0044

Wilson-Kearse, J., 2010. Appalachian state university GEAR UP annual report. Unpublished Report, Appalachian State University, Boone, NC. 